\title{
Yr60, a Gene Conferring Moderate Resistance to Stripe Rust in Wheat
}

S. A. Herrera-Foessel, R. P. Singh, and C. X. Lan, International Maize and Wheat Improvement Center (CIMMYT), 06600 Mexico, D.F., Mexico; J. Huerta-Espino, Campo Experimental Valle de México INIFAP, 56230, Chapingo, Edo de Mexico, Mexico; V. Calvo-Salazar, CIMMYT, Mexico; U. K. Bansal and H. S. Bariana, University of Sydney Plant Breeding Institute-Cobbitty, Narellan, NSW 2567, Australia; and E. S. Lagudah, CSIRO Plant Industry, GPO Box 1600, Canberra, 2601 ACT, Australia

\begin{abstract}
Herrera-Foessel, S. A., Singh, R. P., Lan, C. X., Huerta-Espino, J., Calvo-Salazar, V., Bansal, U. K., Bariana, H. S., and Lagudah, E. S. 2015. Yr60, a gene conferring moderate resistance to stripe rust in wheat. Plant Dis. 99:508-511.

Stripe rust, caused by Puccinia striiformis f. sp. tritici W., is a devastating disease of wheat worldwide. A new stripe rust resistance gene with moderate seedling and adult plant resistance was mapped using an $\mathrm{F}_{5}$ recombinant inbred line (RIL) population developed from the cross of the resistant parent 'Almop' with the susceptible parent 'Avocet'. The parents and RILs were phenotyped for seedling stripe rust response variation in a greenhouse and in field trials at Toluca, Mexico for 2 years. Almop showed moderate levels of resistance at both seedling and adult plant stages compared with the highly susceptible response of Avocet. The distribution of homozygous

resistant, homozygous susceptible, and segregating RILs conformed to segregation at a single locus. Seedlings and adult plant responses were correlated, indicating that the same gene conferred resistance at both stages. A bulk segregant analysis approach with widely distributed simple sequence repeat (SSR) markers mapped the resistance gene to the distal region of the long arm of chromosome 4A. The SSR marker $w m c 776$ cosegregated with this gene, whereas markers $w m c 219$ and $w m c 313$ were tightly linked and both located at 0.6 centimorgans. The resistance locus was designated $\operatorname{Yr} 60$.
\end{abstract}

Stripe or yellow rust, caused by Puccinia striiformis f. sp. tritici W., is one of the most devastating diseases of wheat in various regions worldwide. While historically restricted to more cool and humid areas, the appearance and spread in recent years of more virulent and aggressive races has caused losses in regions where this disease was previously rarely detected (Hovmøller et al. 2008). Although fungicides can be used to control stripe rust, growing resistant cultivars has proven to be the most effective, economical, and environmentally friendly.

Resistance to stripe rust can be categorized as seedling adult plant resistance (APR) based on the growth stage it expresses. Seedling resistance, usually effective during all growth stages of plants, is often qualitatively inherited, race-specific in nature, and easily defeated by the pathogen soon after deployment (McDonald and Linde 2002). APR expresses at postseedling stages and is often quantitatively inherited and has been found in several cases to be durable, even though exceptions were reported (Singh et al. 2011). Of the 67 cataloged stripe rust resistance genes in wheat (McIntosh et al. 2013), most belong to the seedling resistance category.

Common wheat (Triticum aestivum L.) line 'Almop', derived from the cross 'Avocet*3//Lalbmono $1 * 4 /$ Pavon', is moderately resistant to stripe rust in field evaluations conducted in Mexico. The resistance, most likely derived from the chromosome 1B monosomic line of 'Lalbahadur' and transferred to a partially backcrossed substitution line, where chromosome 1B of Mexican 'Pavon 76' substituted the chromosome 1B of the 'Lalbahadur monosomic 1B'. The Lalbahadur monosomic 1B was developed by Dr. R. A. McIntosh, the University of Sydney, Australia from the cross 'Oxley monosomic $1 \mathrm{~B} /$ Kalyansona//5*Lalbahadur' and

Corresponding authors: S. A. Herrera-Foessel; E-mail: sybilherreraf@gmail. com; and R. P. Singh; E-mail: r.singh@ cgiar.org

*The $\boldsymbol{e}$-Xtra logo stands for "electronic extra" and indicates that two supplementary figures are published online.

Accepted for publication 11 December 2014.

http://dx.doi.org/10.1094/PDIS-08-14-0796-RE

(C) 2015 The American Phytopathological Society used initially at International Maize and Wheat Improvement Center (CIMMYT) for mapping the pleiotropic slow rusting resistance gene Lr46/Yr29 (William et al. 2003). While developing the nearisogenic line for $L r 46 / Y r 29$ in 'Avocet' background, some $\mathrm{BC}_{2-}$ derived $\mathrm{F}_{3}$ families lacked $L r 46 / Y r 29$ but carried an unidentified gene which conferred moderate resistance to stripe rust but not to leaf rust.

The objectives of our study were to investigate the genetic basis of resistance to stripe rust in wheat line Almop using a recombinant inbred line (RIL) population from the cross with the susceptible line Avocet, and to determine the chromosomal location of this gene, hereby designated as $\operatorname{Yr} 60$, using molecular markers.

\section{Materials and Methods}

Plant materials. We developed and used $148 \mathrm{~F}_{5}$ RILs from the cross of susceptible parent Avocet (CIMMYT germplasm identification number [GID] 5934038) and the Yr60-carrying line Almop (GID 5934039). The population was generated from three different $F_{1}$ plants from the same cross. Generation advancement was conducted through a pedigree method, where one spike was harvested in each generation from $\mathrm{F}_{2}$ to $\mathrm{F}_{4}$ and, subsequently, hill plots were harvested as bulk to obtain $\mathrm{F}_{4}$-derived $\mathrm{F}_{5}$ seed. The population development was conducted under rust-free conditions in order to avoid genetic drift.

Characterization of $\operatorname{Yr60}$ at the adult plant stage. The parents and RILs were evaluated under artificially inoculated field trials at the CIMMYT research station at Toluca, Mexico during the 2008 and 2009 crop seasons. Approximately 60 seeds of each parent and RILs were sown in 70-cm-long plots on top of 75-cm-wide raised beds as paired rows, with $20-\mathrm{cm}$ spacing and a $50-\mathrm{cm}$ pathway. Spreader rows comprising a mixture of six susceptible lines derived from the cross 'Avocet/Attila', carrying Yr27 but differing in phenology, were sown around the experimental field and as hills on one side of each plot to assure a uniform long-duration stripe rust epidemic. In 2009, one additional wheat line, 'Avocet+Yr31', was included in the mixed spreader. Mexican $P$. striiformis isolate Mex96.11 was used in 2008 for inoculations of spreaders and hills, whereas a mixture of isolates Mex96.11 and Mex08.13 was used in 2009. The main difference between the two races is that Mex96.11 is virulent to $Y r 27$ and avirulent to $\operatorname{Yr31}$, whereas Mex08.13 is the opposite. To initiate the epidemic, 4-week-old spreaders and hills were sprayed three times at 2- to 3-day 
intervals with urediniospores suspended in lightweight mineral oil Soltrol 170 (www.Chempoint.com). Stripe rust severity and host response to infection (reaction) for RILs and parents were scored according to the modified Cobb Scale (Peterson et al. 1948) and Roelfs et al. (1992). Each RIL was scored as homozygous resistant when all plants were resistant, homozygous susceptible when all plants were susceptible, or segregating when both resistant and susceptible plants occurred.

Characterization of Yr60 at the seedling stage. The parents and the complete RIL population were evaluated at the seedling stage in the greenhouse at El Batán, Mexico during February 2011 against $P$. striiformis isolate Mex96.11, one of the races used in the field trials. Approximately 10 seeds of each entry were sown as hills in flat trays. A stripe rust differential set of 30 lines that carried different resistance genes, most of them in Avocet background, were also sown as checks in the same experiment to confirm the purity of the isolate. Plants were inoculated with urediniospores suspended in Soltrol at the two-leaf stage using an atomizer and then placed for incubation in dark in a dew chamber maintained at $7^{\circ} \mathrm{C}$ for $48 \mathrm{~h}$. Plants were then transferred to a greenhouse, where a data logger (LogTag analyzer, ver. 1.9 ) measured the temperature every 15 min until the infection type was recorded. Minimum, maximum, and average temperatures in the greenhouse were 12,27 , and $19^{\circ} \mathrm{C}$, respectively. The infection types were recorded at 15 days postinoculation using a 0-to- 9 scale described by McNeal et al. (1971), where $0=$ no visible symptoms, $1=$ necrotic or chlorotic flecks without sporulation, $2=$ necrotic and chlorotic blotches without sporulation, $3=$ necrotic or chlorotic blotches or stripes with trace sporulation, $4=$ necrotic or chlorotic blotches or stripes with light sporulation, $5=$ necrotic or chlorotic blotches or stripes with intermediate sporulation, $6=$ chlorotic stripes with moderate sporulation, $7=$ stripes with slight chlorosis with abundant sporulation, $8=$ stripes without chlorosis and abundant sporulation, and $9=$ stripes without chlorosis and profuse sporulation. Infection types 7 to 9 were considered as susceptible and all other infection types were considered as resistant. More than one infection type was considered as a range. The trial was repeated once to validate the results.

Molecular mapping of Yr60. About 20 to 30 seeds of parents and RILs were grown in pots under disease free conditions in a greenhouse. The leaf tissue of each entry was harvested, lyophilized, and ground. A cetyltrimethylammonium bromide protocol (CIMMYT 2005) was used for the DNA extraction. More than 500 simple sequence repeat (SSR) markers selected based on Somers et al. (2007) and widely distributed along the wheat genome were applied on the parents to search for polymorphism. Polymerase chain reactions (PCR) were based on standard methods (CIMMYT 2005). The PCR products were separated on 12\% acrylamide gels (29:1) and visualized by silver staining. The resistant and a susceptible DNA bulks were prepared from five resistant and six susceptible RILs, respectively. The SSR markers found to be polymorphic on the parents were then genotyped on the two bulks. Markers identified to be polymorphic on the parents and bulks were screened on the entire RIL population. Grain genes 2.0 (http://wheat.pw.usda.gov/GG2/ index.shtml) was used for identifying additional markers that could saturate the genomic region of Yr60 on chromosome 4AL. In addition, four polymorphic STS markers (Diversity Array Technologyderived and gene-based markers) on chromosome 4AL, provided by the University of Sydney Plant Breeding Institute-Cobbitty, were applied on the RIL population to investigate the relationship of $\operatorname{Yr} 60$ with $\operatorname{Yr} 51$, a gene known to be located in the same chromosome arm.

Statistical analyses. The goodness of fit of the observed phenotypic ratio in the field and greenhouse trials with the expected ratio for the segregation of a single resistance gene in a population at $\mathrm{F}_{5}$ generation was performed using the $\chi^{2}$ test function in Excel. The ICIMapping 3.2 (http://www.isbreeding.net) software was used for the development of linkage maps. The Kosambi mapping function was used to calculate the genetic distances between markers and Yr60. The grouping was based on a $3.0 \mathrm{log}$ of odds threshold and the ripple command was used for confirming the order of the markers. The linkage map was drawn using MapChart (Voorrips 2002). To determine the degree of agreement between field and greenhouse evaluations, we performed a Kendall's $\tau$ correlation test with the CORR procedure of SAS statistical software (ver. 9.3; SAS Institute Inc. 2011).

\section{Results}

Effect of Yr60 at the adult plant stage. The susceptible parent Avocet displayed 90 to $100 \%$ stripe rust severity, with susceptible host response to infection in field trials conducted during both seasons. In contrast, the resistant parent Almop displayed severities of 20 to $50 \%$ in the field, with moderately resistant host response depending on the crop season and time of scoring (Supplementary Figs. S1 and S2). The classification into homozygous resistant, homozygous susceptible, and segregating coincided for most of the RILs during both seasons, with the exception of eight lines. These exceptions were either that they were segregating or homozygous susceptible, or segregating or homozygous resistant. For the remaining 140 RILs, the distribution of homozygous resistant (66 RILs), homozygous susceptible (53 RILs), and segregating (21 RILs) conformed to the ratio expected for segregation at a single locus $\left(\chi_{7: 2 \cdot 7}^{2}=2.18\right.$, $P_{2 d f}=0.34$ ).

Effect of $\operatorname{Yr60}$ at the seedling stage. In the seedling tests conducted in the greenhouse trials, the resistant parent Almop displayed a moderately resistant infection type of 5-6 whereas Avocet displayed a susceptible infection type of 7-8. The infection types of RILs varied from 4-5 to 5-6 for homozygous resistant (81 RILs in total) and 7-8 for the homozygous susceptible (52 RILs), or had a mix of these responses for the segregating RILs (11 RILs). All the RILs determined as homozygous resistant in the field had the same response in the greenhouse. However, 11 RILs that were classified as segregating in the field were scored as homozygous resistant in the greenhouse; hence, based on the greenhouse test, the $\chi^{2}$ goodness of fit could only be met at the $1 \%$ significance level $\left(\chi_{7: 2: 7}^{2}=10.18\right.$, $\left.P_{2 d f}=0.01\right)$. Still, the Kendall's $\tau$ correlation coefficient showed a highly significant agreement $(\tau=0.92, P<0.0001, n=139)$ between field and greenhouse response for the $\mathrm{F}_{5}$ RILs. Hence, the distribution of intermediate (resistant) versus high infection type of the $\mathrm{F}_{5}$ lines evaluated in the greenhouse was in accordance with the field response. In addition, of the eight RILs that showed inconsistent response in the field (and, hence, were not used in the linkage analysis), four were classified as homozygous resistant, two as homozygous susceptible, one as segregating, and one as missing (seed did not germinate).

Mapping of Yr60. Seven polymorphic molecular markers located on chromosome 4AL differentiated the resistant and susceptible bulks and three SSR markers were closely associated with the resistance gene Yr60 based on 140 RILs (Fig. 1). The marker wmc776 cosegregated with $\mathrm{Yr60}$, and both $w m c 313$ and $w m c 219$ were mapped at 0.6 centimorgans $(\mathrm{cM})$ distal to $\operatorname{Yr} 60$.

\section{Discussion}

We identified and mapped an uncharacterized stripe rust resistance gene, $\mathrm{Yr} 60$, which conferred moderate levels of resistance at both seedlings and adult plant stages against the two Mexican races of $P$. striiformis. Few exceptions were found among RILs scored during two cycles of field evaluations versus greenhouse results. The environmental effect is expected to be large for a gene that shows intermediate effect, resulting in a more narrow reaction range between the two parents. A smaller sample number of about 10 seedlings in the greenhouse could perhaps also explain the differences with the field results. Nevertheless, the field and greenhouse response were highly correlated, indicating that the same gene conferred resistance at both stages. $\operatorname{Yr} 60$ was derived from Almop and is now present in Avocet background, where several other stripe rust resistance genes have been transferred to develop a near-isogenic differential series (Wellings et al. 2000). Yr60 was mapped to the distal end of chromosome arm $4 \mathrm{AL}$ and was tagged with three tightly linked microsatellite markers ( $w m c 776, w m c 219$, and $w m c 313$ ) using $140 \mathrm{~F}_{5}$ RILs. Marker $w m c 776$ was absent in Lalbahadur, indicating that this parent most likely did 
not contribute $\operatorname{Yr} 60$. The origin of $\operatorname{Yr} 60$ and its presence in other genetic background remains unknown. Seed of the Lalbahadur monosomic 1B line was not available for the test to determine the origin of resistance gene in Almop.

Of the cataloged stripe rust resistance genes, only $\operatorname{Yr} 51$ has been mapped thus far to chromosome 4AL. Yr51 was identified in wheat landrace 'AUS27858' from Pakistan and confers an infection type of ;1-N to $2 \mathrm{C}$ on the 0-to-4 scale (Randhawa et al. 2014), whereas Yr60 displayed an infection type ranging between 4-5 to 5-6 based on a 0 to- 9 scale, which is equivalent to 2 to $2+$ on the 0 -to- 4 scale. The closest marker for $Y r 51$ is sun104, with a distance of $2.5 \mathrm{cM}$ (Randhawa et al. 2014); and, according to the present study, Yr60 is approximately $10.1 \mathrm{cM}$ distal to $\operatorname{Yr} 51$. The different genetic positions and seedling infection types displayed by the two genes indicated that Yr51 and Yr60 are different resistance genes.

Additional resistance genes in wheat are also reported in similar genomic regions as $\operatorname{Yr60}$. A minor quantitative trait locus for APR to stripe rust with consistent effects at early scoring dates was reported in a similar region in an 'Avocet/Kariega' population (Prins et al. 2011; Ramburan et al. 2004). Markers wmc313 and wmc219 were previously reported to be tightly linked at 0.3 to $0.5 \mathrm{cM}$ and 1 to $1.1 \mathrm{cM}$, respectively, with the Septoria tritici blotch resistance gene Stb7 in two populations, 'ST6/Katepwa' and 'ST6/Erik' (McCartney et al. 2003). In addition, the leaf rust resistance gene Lr28, originating from Aegilops speltoides, was also shown to be linked with wmc313 at $5 \mathrm{cM}$ in the 'HD2329/HW2037' population (Bipinraj et al. 2011).

Yr60, by itself, imparted only a moderate level of resistance, which is also known for other characterized seedling rust resistance genes. Even if the impact of $\operatorname{Yr} 60$ in preventing the epidemic development or obviating the use of fungicides is expected to be small compared with a seedling gene of major effect, it still can be useful in gene combinations. Of the previously cataloged seedling or APR race-specific stripe rust resistance genes, few have been identified to be of intermediate effect (McIntosh et al. 1995). Yr28 in 4DS and Yr31 in 2BS give similar effects to $\operatorname{Yr} 60$ on seedlings and adult plants (Singh et al. 2000, 2003; Wellings et al. 2000). Yr31 is known to interact with additional APR genes to reach high levels of resistance such as in CIMMYT lines 'Pastor' and 'Chapio' (Rosewarne et al. 2012; Yang et al. 2013). Markers associated with $\operatorname{Yr} 60$ identified in this study, together with available markers for the known APR genes such as Lr34/ Yr18, Lr46/Yr29, and $L r 67 / Y r 46$, can be used in a similar way to incorporate high levels of stripe rust resistance in breeding programs. However, as for all seedling race-specific resistance genes, caution should be taken, in particular if deployed singly. Virulence to $\operatorname{Yr} 31$ was detected in Mexico in 2009 (Rosewarne et al. 2012), whereas virulence

\section{AL}

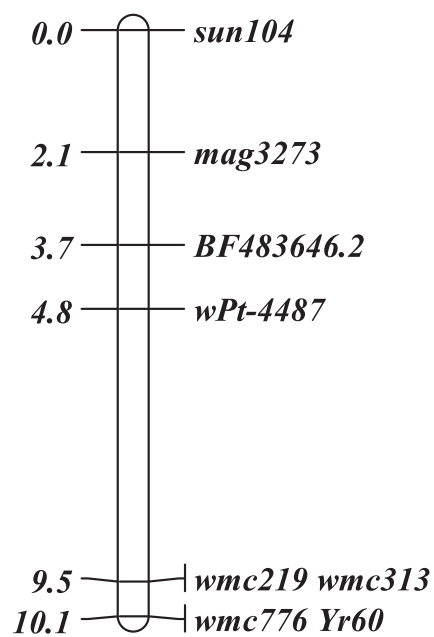

Fig. 1. Linkage map of $\mathrm{Yr} 60$ in $4 \mathrm{AL}$ using $140 \mathrm{~F}_{5}$ recombinant inbred lines from the 'Avocet' $\times$ 'Almop' cross. for Yr60 is thus far not known. The Lalbahadur (Pavon 1B) parent of Almop, possessing both $L r 46 / Y r 29$ and $Y r 60$, will be a better parent for breeding because it has displayed a much higher level of resistance in our field trials than for lines with the two genes alone (data not presented).

The resistance mechanism of a seedling resistance gene with intermediate response in the greenhouse or field is not known; however, a weak recognition between effector and resistance elicitor can be hypothesized. Our experience with $\operatorname{Yr} 31$ has shown that the level of resistance increases when moderately effective race-specific genes are combined with APR genes; however, they eventually succumb to new races due to mutations from avirulence to virulence and selection in the pathogen population.

\section{Acknowledgments}

We thank the Grains Research and Development Corporation (GRDC) of Australia for the financial support of this study.

\section{Literature Cited}

Bipinraj, A., Honrao, B., Prashar, M., Bhardwaj, S., Rao, S., and Tamhankar, S 2011. Validation and identification of molecular markers linked to the leaf rust resistance gene $L r 28$ in wheat. J. Appl. Genet. 52:171-175.

CIMMYT. 2005. Laboratory Protocols, CIMMYT Applied Molecular Genetics Laboratory, third ed. CIMMYT, Mexico, D.F.

Hovmøller, M. S., Yahyaoui, A. H., Milus, E. A., and Justesen, A. F. 2008. Rapid global spread of two aggressive strains of a wheat rust fungus. Mol. Ecol. 17: 3818-3826.

McCartney, C. A., Brûlé-Babel, A. L., Lamari, L., and Somers, D. J. 2003 Chromosomal location of a race-specific resistance gene to Mycosphaerella graminicola in the spring wheat ST6. Theor. Appl. Genet. 107:1181-1186.

McDonald, B. A., and Linde, C. 2002. The population genetics of plant pathogens and breeding strategies for durable resistance. Euphytica 124:163-180.

McIntosh, R. A., Dubcovsky, J., Rogers, W. J., Morris, C., Appels, R., and Xia X. C. 2013. Catalogue of Gene Symbols for Wheat: 2013-2014 Supplement Online publication. http://wheat.pw.usda.gov/GG2/Triticum/wgc/2013/20132014_Supplement.pdf

McIntosh, R. A., Wellings, C., and Park, R. 1995. Wheat Rusts: An Atlas of Resistance Genes. Kluwer Academic Publishers, Dordrecht, The Netherlands.

McNeal, F. H., Konzak, C. F., Smith, E. P., Tate, W. S., and Russell, T. S. 1971 Pages 34-412 in: A Uniform System for Recording and Processing Cereal Research Data. U. S. Dep. Agric. Agric. Res. Serv. Bull. Washington, DC.

Peterson, R., Campbell, A., and Hannah, A. 1948. A diagrammatic scale for estimating rust intensity on leaves and stems of cereals. Can. J. Res. 26c: 496-500.

Prins, R., Pretorius, Z. A., Bender, C. M., and Lehmensiek, A. 2011. QTL mapping of stripe, leaf and stem rust resistance genes in a Kariega $\times$ Avocet $S$ doubled haploid wheat population. Mol. Breed. 27:259-270.

Ramburan, V. P., Pretorius, Z. A., Louw, J. H., Boyd, L. A., Smith, P. H., Boshoff, W. H., and Prins, R. 2004. A genetic analysis of adult plant resistance to stripe rust in the wheat cultivar Kariega. Theor. Appl. Genet. 108: 1426-1433.

Randhawa, M., Bansal, U., Valárik, M., Klocová, B., Doležel, J., and Bariana, H 2014. Molecular mapping of stripe rust resistance gene Yr51 in chromosome 4AL in wheat. Theor. Appl. Genet. 127:317-324.

Roelfs, A., Singh, R., and Saari, E. 1992. Rust Diseases of Wheat: Concepts and Methods of Disease Management. CIMMYT, Mexico D.F.

Rosewarne, G. M., Singh, R. P., Huerta-Espino, J., Herrera-Foessel, S. A., Forrest, K. L., Hayden, M. J., and Rebetzke, G. J. 2012. Analysis of leaf and stripe rust severities reveals pathotype changes and multiple minor QTLs associated with resistance in an Avocet $\times$ Pastor wheat population. Theor. Appl. Genet. 124: 1283-1294.

SAS Institute Inc. 2011. SAS/STAT(R) 9.3 User's Guide. SAS Institute Inc., Cary, NC.

Singh, R. P., Huerta-Espino, J., Bhavani, S., Herrera-Foessel, S. A., Singh, D. Singh, P. K., Velu, G., Mason, R. E., Jin, Y., Njau, P., and Crossa, J. 2011. Race non-specific resistance to rust diseases in CIMMYT spring wheats. Euphytica 179:175-186.

Singh, R. P., Nelson, J. C., and Sorrells, M. E. 2000. Mapping Yr28 and other genes for resistance to stripe rust in wheat. Crop Sci. 40:1148-1155.

Singh, R. P., William, H. M., and Huerta-Espino, J. 2003. Identification and mapping of gene Yr31 for resistance to stripe rust in Triticum aestivum cultivar Pastor. Pages 411-413 in: Proc. 10th Int. Wheat Genet. Symp. N. E. Pogna, M. Romana, E. A. Pogna, and G. Galterio, eds. Instituto Sperimentale per la Cerealicoltura, Rome.

Somers, D. J., Banks, T., Depauw, R., Fox, S., Clarke, J., Pozniak, C., and McCartney, C. 2007. Genome-wide linkage disequilibrium analysis in bread wheat and durum wheat. Genome 567:557-567.

Voorrips, R. 2002. MapChart: Software for the graphical presentation of linkage maps and QTLs. J. Hered. 93:77-78.

Wellings, C. R., Singh, R. P., McIntosh, R. A., and Yahyaoui, A. 2000. The assessment and significance of pathogenic variability in Puccinia 
striiformis in breeding for resistance to stripe (yellow) rust: Australia and international studies. Pages 134-143 in: The Eleventh Regional Wheat Workshop for Eastern, Central, and Southern Africa. Addis Ababa, Ethiopia.

William, M., Singh, R. P., Huerta-Espino, J., Ortiz Islas, S., and Hoisington, D. 2003. Molecular marker mapping of leaf rust resistance gene $L r 46$ and its association with stripe rust resistance gene $Y r 29$ in wheat. Phytopathology 93:153-159.

Yang, E. N., Rosewarne, G. M., Herrera-Foessel, S. A., Huerta-Espino, J., Tang, Z. X., Sun, C. F., Ren, Z. L., and Singh, R. P. 2013. QTL analysis of the spring wheat "Chapio" identifies stable stripe rust resistance despite inter-continental genotype $\times$ environment interactions. Theor. Appl. Genet. 126:1721-1732. 